\title{
Tectônica do patrimônio industrial moderno: Fábrica da Bombril Nordeste, em Abreu e Lima [PE]
}

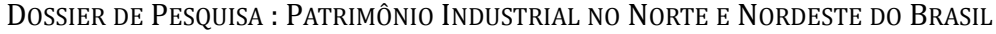

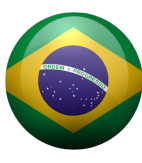

\section{Alcilia Afonso de Albuquerque e Melo}

Doutora em Projetos Arquitetônicos [ESTAB-UPC], Professora Adjunta do curso de Arquitetura e

Urbanismo da Universidade Federal de Campina Grande. Coordenadora do Grupo de Pesquisas Arquitetura e Lugar [GRUPAL]. Campina Grande [PB] Brasil. <kakiafonso@hotmail.com>

\begin{abstract}
Resumo
Este artigo possui como objeto de estudo, a tectônica do patrimônio industrial moderno, tomando como estudo de caso, a Fábrica da Bombril (1979/ 1983) - uma edificação localizada na BR-101 Norte, no município de Abreu e Lima, Região Metropolitana do Recife, Pernambuco. 0 objetivo do trabalho é trazer à tona o debate sobre a dimensão construtiva do patrimônio arquitetônico moderno industrial, as soluções empregadas no partido, em sistemas estruturais, peles, detalhes e na materialidade da obra, que contribuíram para a consolidação de uma linha de projetos desenvolvidos durante a modernidade. Salienta-se que, por ocasião da Conferência 2003 do TICCIH - The International Committee for the Conservation of the Industrial Heritage (Comissão Internacional para a Conservação do Patrimônio Industrial), foi extraído um documento, intitulado Carta de Nizhny Tagil (2003) que colocou que, todo o acervo do patrimônio industrial deve ser estudado, a sua história deve ser ensinada, a sua finalidade e o seu significado devem ser explorados e clarificados a fim de serem dados a conhecer ao grande público. Tal artigo trata-se de um dos resultados de investigações realizadas pelo Grupo de pesquisa Arquitetura e Lugar cadastrado na UFCG e no CNPq, que vem procurando resgatar, tanto a produção moderna, quanto àquela referente ao acervo arquitetônico industrial regional, realizando para isso, diálogos com pesquisadores que trataram dos temas, mesmo que com distintos enfoques.
\end{abstract}

\section{Palavras-chave}

Tectônica. Patrimônio arquitetônico industrial. Modernidade.

\section{Tectonics of modern industrial heritage: Factory of "Bombril Nordeste", in "Abreu e Lima" city [state of Pernambuco, Brazil].}

\begin{abstract}
This article presents the tectonics of the modern industrial patrimony, taking as a case study the Bombril Factory (1979/1983) - a building located at BR-101 Norte, in the city of "Abreu e Lima", Metropolitan Region of Brazil, Recife, Pernambuco. The objective of this work is to bring to the surface the debate on the constructive dimension of the modern industrial architectural patrimony, the solutions employed in the party, in structural systems, skins, details and in the materiality of the work, which contributed to the consolidation of a line of developed projects during modern times. At the 2003 Conference of the International Committee for the Conservation of Industrial Heritage (TICCIH), a document was drawn up, entitled Letter from Nizhny Tagil (2003), which , the entire heritage of industrial heritage must be studied, its history must be taught, its purpose and its meaning must be explored and clarified in order to be known to the general public. This article is one of the results of research carried out by the Research Group Architecture and Place registered at the UFCG and CNPq, which has sought to recover both the modern production and the one related to the regional industrial architectural collection, with researchers who dealt with the themes, even with different approaches.
\end{abstract}

\section{Keywords}

Tectonics. Industrial architectural patrimony. Modernity. 


\section{Introdução}

Este artigo possui como objeto de estudo, a tectônica do patrimônio industrial moderno, tomando como estudo de caso, a Fábrica da Bombril (1979/ 1983) - uma edificação localizada na BR-101 Norte, no município de Abreu e Lima, Região Metropolitana do Recife, Pernambuco.

O objetivo do trabalho é trazer à tona o debate sobre a dimensão construtiva do patrimônio arquitetônico moderno industrial, as soluções empregadas no partido, em sistemas estruturais, peles, detalhes e na materialidade da obra, que contribuíram para a consolidação de uma linha de projetos desenvolvidos durante a modernidade.

Salienta-se que, por ocasião da Conferência 2003 do TICCIH - The International Committee for the Conservation of the Industrial Heritage (Comissão Internacional para a Conservação do Patrimônio Industrial), foi extraído um documento, intitulado Carta de Nizhny Tagil (2003) que colocou que, todo o acervo do patrimônio industrial deve ser estudado, a sua história deve ser ensinada, a sua finalidade e o seu significado devem ser explorados e clarificados, a fim de serem dados a conhecer ao grande público.

Tal artigo trata-se de um dos resultados de investigações realizadas pelo Grupo de Pesquisa Arquitetura e Lugar cadastrado na Universidade Federal de Campina Grande (UFCG) e no Conselho Nacional de Desenvolvimento Científico e Tecnológico (CNPq), que vem procurando resgatar, tanto a produção moderna, quanto àquele referente ao acervo arquitetônico industrial regional, realizando para isso, diálogos com pesquisadores que trataram dos temas, mesmo que com distintos enfoques.

As pesquisas de campo e as pesquisas bibliográficas, a fim de buscar nessa produção, pontos convergentes nas soluções projetuais e construtivas estão em andamento, e a cada dia, informações inéditas nos chegam, nos fazendo acreditar que ainda há muito por ser investigado e debatido para a construção de um possível inventário sobre edificações modernas industriais no nordeste brasileiro.

\section{Relação arquitetura industrial e modernidade}

Considerando-se que as palavras chaves desse trabalho tratam sobre os conceitos de tectônica, patrimônio industrial moderno, e modernidade, inicialmente, procurar-se-á, tecer algumas reflexões sobre a relação existente entre os mesmos.

0 arquiteto Lúcio Costa, definiu arquitetura, "como construção concebida com a intenção de ordenar e organizar plasticamente o espaço, em função de uma determinada época, de um determinado meio, de uma determinada técnica e de um determinado programa".

Parte-se do princípio na elaboração desse artigo, que o fio condutor da discussão está voltado para o entendimento do que vem a ser construir e sua intrínseca relação com a arquitetura, e no caso específico, como se deu esse vínculo em um projeto fabril moderno construído no nordeste brasileiro. Construir, segundo o dicionário Aurélio, significa reunir e dispor metodicamente as partes de um todo, edificar, dispor, organizar. Segundo Sekler (1965):

A construção designa a realização efetiva de uma obra, através de diversos materiais e métodos de montagem. [...] Em resumo podemos dizer: A 'estrutura' como princípio e ordem imanente realizam-se 'pela construção', mas é apenas 'o arquitetônica' que torna visível a estrutura e construção e confere-lhes uma expressão artística (Sekler, 1965).

Parte-se do princípio, assim, que arquitetura é a construção do espaço, e que trabalha com diversas dimensões em seu existir, entre elas a dimensão espacial; estética; técnica; ambiental; econômica; entre outras, conforme colocaram diversos autores, entre eles, Frampton, que em 1995, propôs a tectônica, como a dimensão construtiva da arquitetura, colocando-a em um nível de igualdade com a dimensão espacial e formal, que havia sido privilegiada na modernidade. 
O professor Mahfuz (2003), em artigo "Reflexões sobre a construção da forma pertinente" exaltou a importância da construção para a arquitetura e reconhece como uma das características de autenticidade arquitetônica, a relevância da estrutura resistente na definição de sua estrutura formal.

A materialidade de uma obra é ainda mais importante quando o seu caráter não é definido, a partir do uso de elementos estilísticos extraídos da arquitetura de outros tempos e agregados à estrutura resistente. Em uma arquitetura que aspira a autenticidade, os edifícios são o que são, e não o que aparentam ser (Mahfuz, 2003 p.69).

A tectônica é frequentemente definida como "arte da construção", e um melhor entendimento do seu conceito não pode passar ao lado de uma melhor compreensão da trajetória histórica do termo. Amaral (2009) escreveu um artigo esclarecedor que apresentou uma retomada histórica do termo da tectônica, esclarecendo que o mesmo é derivado do grego tekton (carpinteiro), e que a noção de tectônica atravessou mais de 2.000 anos de história.

Sua compreensão mudou em relação ao original grego, principalmente devido às contribuições dos teóricos alemães Carl Bötticher e Gottfried Semper no século XIX, e, mais recentemente, devido à notável contribuição de K. Frampton (1995). Este último autor provocou uma renovação do debate sobre a tectônica, promovendo a noção ao estatuto de "potencial de expressão construtiva" da arquitetura, capaz de reunir aspectos materiais e construtivos aos aspectos culturais e estéticos.

0 termo é definido como o "caráter essencial da arquitetura através do qual, parte de sua expressividade intrínseca é inseparável da maneira precisa da construção", não mais se apresentando como um manifesto contra o cenográfico e o representacional, como ocorreu no debate inicial de Frampton (1985 e 1990) em seus primeiros textos sobre o tema, onde criticava a produção pós moderna - mas como uma maneira de abordar a arquitetura enquanto concepção e construção, enquanto realização, conjuntamente.

Entendendo que um sistema construtivo é composto não apenas da estrutura da obra em si, com sua divisão básica em subestrutura (fundações), e superestrutura (pilares, vigas, e peles), mas também, de seus detalhes, junções que envolvem as relações entre a materialidade e as soluções projetuais, que formam o arcabouço construtivo de determinada edificação e lhe conferem um valor construtivo a ser preservado.

O conceito de estrutura relacionada à concepção projetual que foi trabalhado por Erico Weidle (1992) esclarece:

Estrutura, em arquitetura, é o sistema material da edificação capaz de transmitir cargas e absorver esforços, de modo a garantir a estabilidade, a segurança e a integridade da construção, cooperando na sua organização espacial e na sua expressão, mediante o adequado emprego de materiais, das técnicas, dos processos e dos recursos econômicos (Weidle, 1992, p.83).

O segundo ponto da discussão, partiu da observação de que a relação entre o edifício industrial e a modernidade é muito próxima e que a adoção da linguagem moderna para edificações de uso industrial foi empregada por mestres e precursores como Walter Gropius e Le Corbusier que enalteceram, em pleno século XX, os edifícios fabris norte americanos e demonstraram o seu entusiasmo pela era da máquina:

Em um movimento de redução de suas formas ao estritamente necessário, o edifício industrial passou, ele próprio, a servir de referência para a Arquitetura Moderna. Esses edifícios tornaram-se fundamentais para as concepções arquitetônicas modernas (Caldas \& Moreira, s./d., p.155).

Observa-se que o edifício industrial adotou como princípio, a racionalização projetual e construtiva, além da busca pelas soluções que demonstrem a verdade arquitetônica e técnica. Pode-se afirmar que as fábricas se desenvolveram como parte dos fenômenos da industrialização e da subsequente mecanização: 
As construções destinadas a acomodar processos produtivos e industriais estão estreitamente ligadas a dois processos ou fenômenos característicos da era moderna: a mecanização e a industrialização, o que qualifica estas construções como uma expressão ou face da modernidade. Arquitetos pensaram esses edifícios de forma a solucionar impasses de ordem técnica. Essas soluções resultaram em significativas conquistas na engenharia civil, tais como o cálculo estrutural, técnicas avançadas com materiais como o ferro e o concreto e a racionalização e padronização dos processos de construção, os quais foram aplicados também a outros edifícios (Caldas \& Moreira, s./d., p.154).

Com a disseminação dos processos de industrialização e mecanização, foram observadas alterações significativas nos modos de construir, ao se explorarem os recursos e tecnologias apropriados para as suas necessidades.

Essa produção arquitetônica industrial acarretou na construção de obras de boa qualidade projetual realizada por arquitetos que buscaram alinhar a concepção do processo industrial aos edifícios, formando assim, um acervo rico que compõe o rol dos bens arquitetônicos do patrimônio moderno industrial.

Fundamental também é definir o que se entende por patrimônio industrial, e para tal, toma-se aqui o conceito trabalhado pela Carta de Nizhny Tagil (2003):

[...] compreende os vestígios da cultura industrial que possuem valor histórico, tecnológico, social, arquitetônico ou científico. Estes vestígios englobam edifícios e maquinaria, oficinas, fábricas, minas e locais de processamento e de refinação, entrepostos e armazéns, centros de produção, transmissão e utilização de energia, meios de transporte e todas as suas estruturas e infraestruturas, assim como os locais onde se desenvolveram atividades sociais relacionadas com a indústria, tais como habitações, locais de culto ou de educação.

Observa-se que muitos destes edifícios ou complexos industriais foram abandonados ao longo dos anos, devido a uma série de fatores de ordem econômica, ou familiares, e grande parte do acervo foi demolido, ou descaracterizado.

Contudo, há uma tendência contemporânea em transformar territórios e patrimônios industriais, dando aos mesmos, novos usos, soluções empregadas especialmente por holandeses, que vem se disseminando por vários países, e que a autora francesa Françoise Choay (2006) discutiu em texto que tratou sobre reuso e requalificação desses espaços, antes industriais.

Choay (2006) colocou que os edifícios isolados, em geral, de construção sólida, sóbria e de manutenção fácil, são facilmente adaptáveis às normas de utilização atuais e se prestam a múltiplos usos públicos e privados, e citou casos norte americanos e europeus, nos quais já são incontáveis os imóveis como usinas, ateliers, entrepostos, transformados em escolas, museus, teatros. 0 conceito de reutilização - reintegração de um edifício desativado a uso normal - é apontado por Choay, como um caminho para a integração do patrimônio industrial à vida contemporânea.

Contudo, felizmente, existem casos nos quais os usos de conjuntos e edifícios industriais vêm sendo mantidos, e as soluções projetuais originais estão conservadas e o espaço projetado encontra-se em pleno funcionamento, permitindo observar nessas obras, a relação existente entre o processo industrial e arquitetura.

Como estudo de caso que exemplifica de forma significativa essa relação, foi selecionada para ser apresentada neste evento, a Fábrica da Bombril, projetada entre os anos de 1979 a 1983, pelo arquiteto Acacio Gil Borsoi, que contou com a colaboração das arquitetas Janete Costa e Rosa Aroucha.

\section{Breve histórico da empresa Bombril}

Torna-se necessário aqui, esclarecer sobre a origem da empresa Bombril no Brasil, para o entendimento sobre o processo que criou a Unidade Fabril no Estado de Pernambuco, contextualizando 
o objeto de estudo. Será visto um pouco sobre a história dessa indústria e posteriormente, analisarse-á, a sua solução arquitetônica, que adotou como linguagem os princípios de modernidade, especificamente, do brutalismo.

A Bombril é uma empresa do setor de higiene e limpeza doméstica, cujo principal produto é uma lã de aço, que é utilizada como produto de limpeza, específico para panelas. Foi fundada em 14 de janeiro de 1948, no bairro do Brooklin em São Paulo, por Roberto Sampaio Ferreira que a denominou "Abrasivos Bombril Ltda", e produziu a lã de aço, inspirando-se no novo produto fabricado, originalmente, nos Estados Unidos (Figura 1). 0 lançamento no Brasil foi uma revolução para as donas de casa daquela época, porque, além de polir panelas, o produto limpava vidros, louças, azulejos e ferragens, ficando conhecido como "1001 utilidades". 0 produto foi um sucesso, e somente naquele ano, foram vendidas 48 mil unidades (Figura 2).

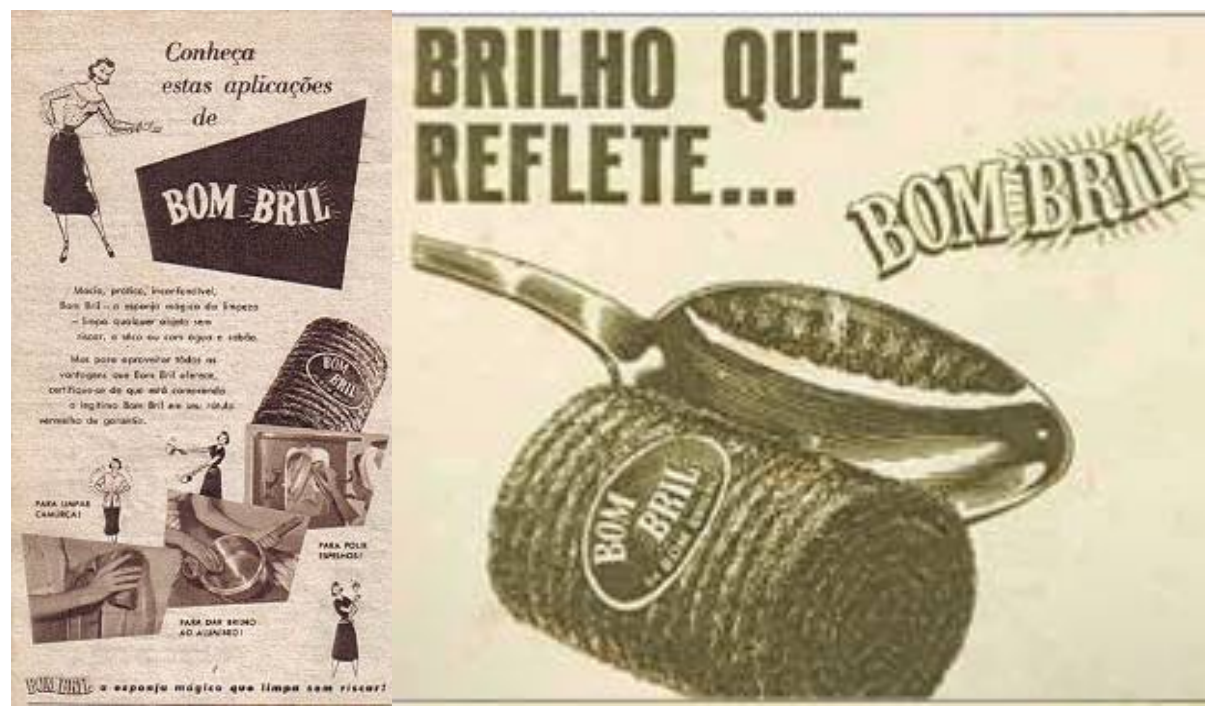

Figura 1. Os primeiros produtos da Bombril. Fonte: Site da empresa Bombril http://www.bombril.com.br/sobre/empresa
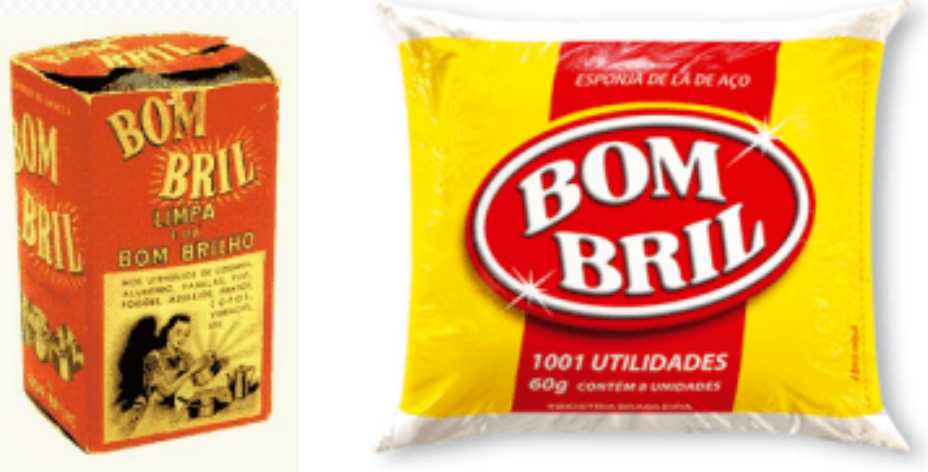

Figura 2. Evolução histórica da embalagem da lã de aço Bombril. Fonte: Site da empresa Bombril http://www.bombril.com.br/sobre/empresa

Em 1961, a Bombril adquiriu a Companhia de Produtos Químicos - Fábrica Belém, detentora das marcas Sapólio e Radium de saponáceos em pedra, passando a desenvolver e aprimorar a linha Sapólio Radium, incluindo uma versão cremosa. Antes de ser lançado no Brasil, o produto existia apenas na França, Holanda e Bélgica.

Em 1972, a Bombril incorporou a Indústria de Lã de Aço Mimosa Ltda., do Rio de Janeiro, e em 1973 , foi a vez da Q'Lustro, empresa que detinha aproximadamente $25 \%$ do mercado nacional de lã de aço.

Em 1976, Bombril mudou sua linha de produção do bairro do Brooklin, em São Paulo, para a moderna fábrica em São Bernardo do Campo, cidade próxima à capital. Essa unidade existe até 
hoje e é considerada a matriz da Bombril, que atualmente possui 3 complexos industriais no Brasil: um em São Bernardo do Campo [SP], outro em Sete Lagoas [MG], e este que está aqui sendo analisado, localizado no município de Abreu e Lima [PE].

Em 1978,a Bombril lançou o detergente Limpol. Na sequência, vieram os desinfetantes (Pinho e Kalipto), os amoniacados (Fort) e os plásticos (embalagens de lixo e esponja de espuma). Neste mesmo ano, o ator Carlos Moreno surgiu por primeira vez como Garoto Bombril e as vendas da Lã de Aço Bombril chegaram à marca de 420 milhões de unidades.

Em 1981, Roberto Sampaio Ferreira, o fundador da Bombril faleceu e, em primeiro de junho de 1982, foi constituída a Bombril Indústria e Comércio Ltda. Em 1983, inaugurou-se a Bombril Química, em Simões Filho, Bahia, e mais produtos foram lançados, tais como o Amaciante Mon Bijou e a Esponja de Lã de Aço Bombril numa versão com sabão.

Em 1984, foi inaugurada a Bombril Nordeste, em Abreu e Lima, zona metropolitana de Recifeobjeto de estudo desse artigo - e a razão social mudou para Bombril S/A, quando a empresa passou a ter ações negociadas na Bolsa de Valores. Esta unidade possui uma área construída de $20.295 \mathrm{~m}^{2}$, em um terreno de $74 \mathrm{mil} \mathrm{m}^{2}$. Atualmente, a fábrica de Abreu e Lima responde por $20 \%$ de tudo que a Bombril produz.

Em 1987, mais uma inauguração, agora da Bombril Minas, em Sete Lagoas [MG] e em 1999, a marca Bombril foi considerada a "Marca do Século".

Em 1990, o grupo italiano Ferruzzi adquiriu 2/3 das ações da Bombril e, em 1991, a Cragnotti \& Partners obtém o seu controle acionário. Nos últimos anos da década de 90 do século XX, a empresa entrou em um processo de dificuldades financeiras, mas a família interviu a fim de não perder o patrimônio familiar herdado.

Em 2006, Ronaldo Sampaio Ferreira assumiu o controle da empresa, resgatando o pioneirismo do seu pai, fundador da Bombril e a partir de então, a indústria conseguiu de estabilizar financeiramente e continuar seu padrão de qualidade, ocupando novamente seu lugar no mercado.

\section{A fábrica da Bombril em Abreu e Lima (1979-1983)}

Após o breve histórico da empresa Bombril, ver-se-á aqui as questões que tratam especificamente, da Unidade fabril pernambucana, esclarecendo-se inicialmente, estudos que foram realizados sobre o complexo fabril e seus respectivos enfoques.

O projeto da Unidade fabril da Bombril em Pernambuco (Figura 3) foi realizado pelo arquiteto Acácio Gil Borsoi, com colaboração das arquitetas Janete Costa e Rosa Aroucha, em 1979, tendo sua construção concluída em 1983, pela construtora OAS - e a inauguração ocorrida em 1984.

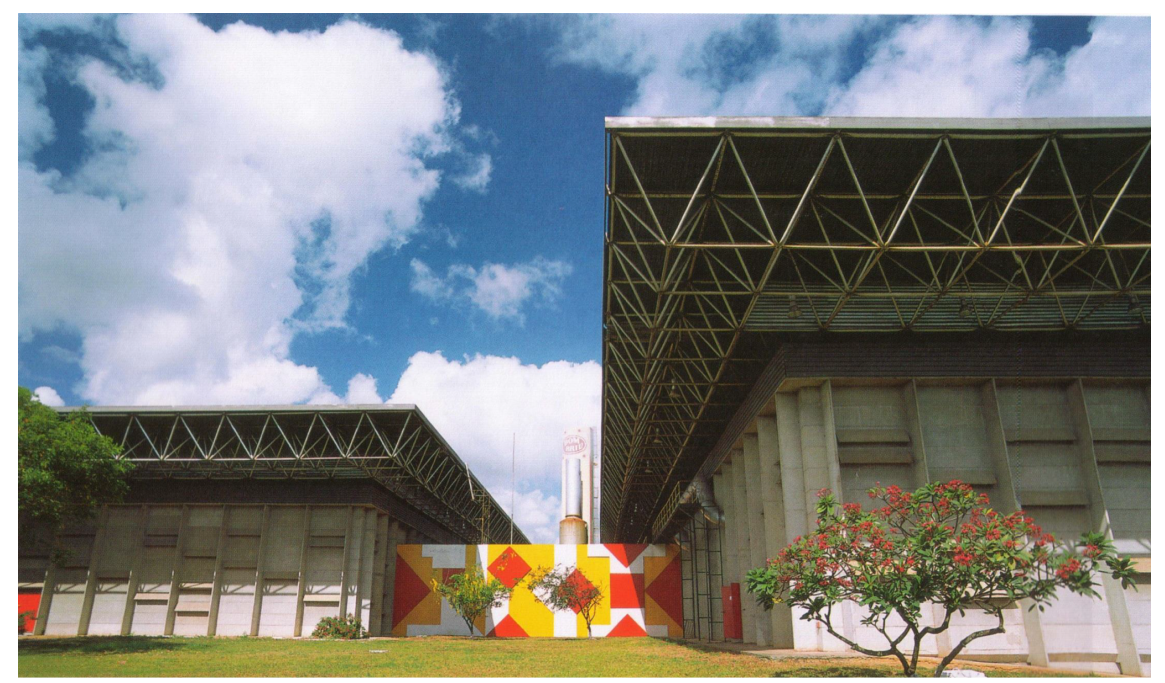

Figura 3. Fábrica da Bombril em Pernambuco. Fonte: Caldas, 2010. 


\subsection{Antecedentes da pesquisa}

Alguns pesquisadores pernambucanos trataram sobre a obra que é uma referência em relação à arquitetura industrial, à obra do escritório de Acacio Gil Borsoi e às soluções de detalhes pré-fabricados empregados.

Amaral (2001) escreveu um artigo sobre esta fábrica para o seminário nacional do Docomomo Brasil, realizado em Viçosa, em 2001, que tratava sobre o processo de industrialização brasileira e as novas técnicas construtivas relacionadas com a modernidade. No artigo apresentado, Amaral escreveu sobre o que ela denominou um "processo caboclo de industrialização", considerando as dificuldades locais da época da construção do arrojado projeto, para execução do sistema construtivo adotado.

Nove anos após, Caldas (2010) apresentou uma dissertação de mestrado na UFPE sobre o tema da "Arquitetura industrial em Recife: Uma face da Modernidade" que possuía como objetivo "esclarecer alguns dos mecanismos ou recursos utilizados para qualificar determinados edifícios, como objetos arquitetônicos", e para tal, a autora analisou um grupo específico de edifícios industriais, através de uma abordagem acerca das técnicas e dos sistemas construtivos nele aplicados, estando entre eles, o conjunto da Fábrica da Bombril.

Caldas \& Moreira (2012) - mestranda e orientador na época - escreveram juntos um artigo resultante dessa pesquisa de mestrado, objetivando analisar edifícios industriais por meio de uma abordagem das técnicas e dos sistemas construtivos neles aplicados, tendo como objeto de estudo três edifícios construídos na Região Metropolitana do Recife, entre 1960 e 1980, estando a Fábrica da Bombril aí presente. 0 artigo resulta da Dissertação de Mestrado e - de forma sucinta - chama a atenção para os principais pontos daquela pesquisa.

Contudo, bem antes desses trabalhos acadêmicos, a revista Projeto - em 1985 (Figura 4) publicou uma matéria intitulada "Edifício Industrial: Adequação ao clima em solução industrial modulada, Bombril Nordeste" (1985, pp. 56-57) enfocando as soluções projetuais e construtivas da arrojada obra. Esta matéria é importante, pois foi escrita baseada em depoimentos do próprio autor, e por isso, será neste trabalho a principal fonte coletada para análise da mesma.

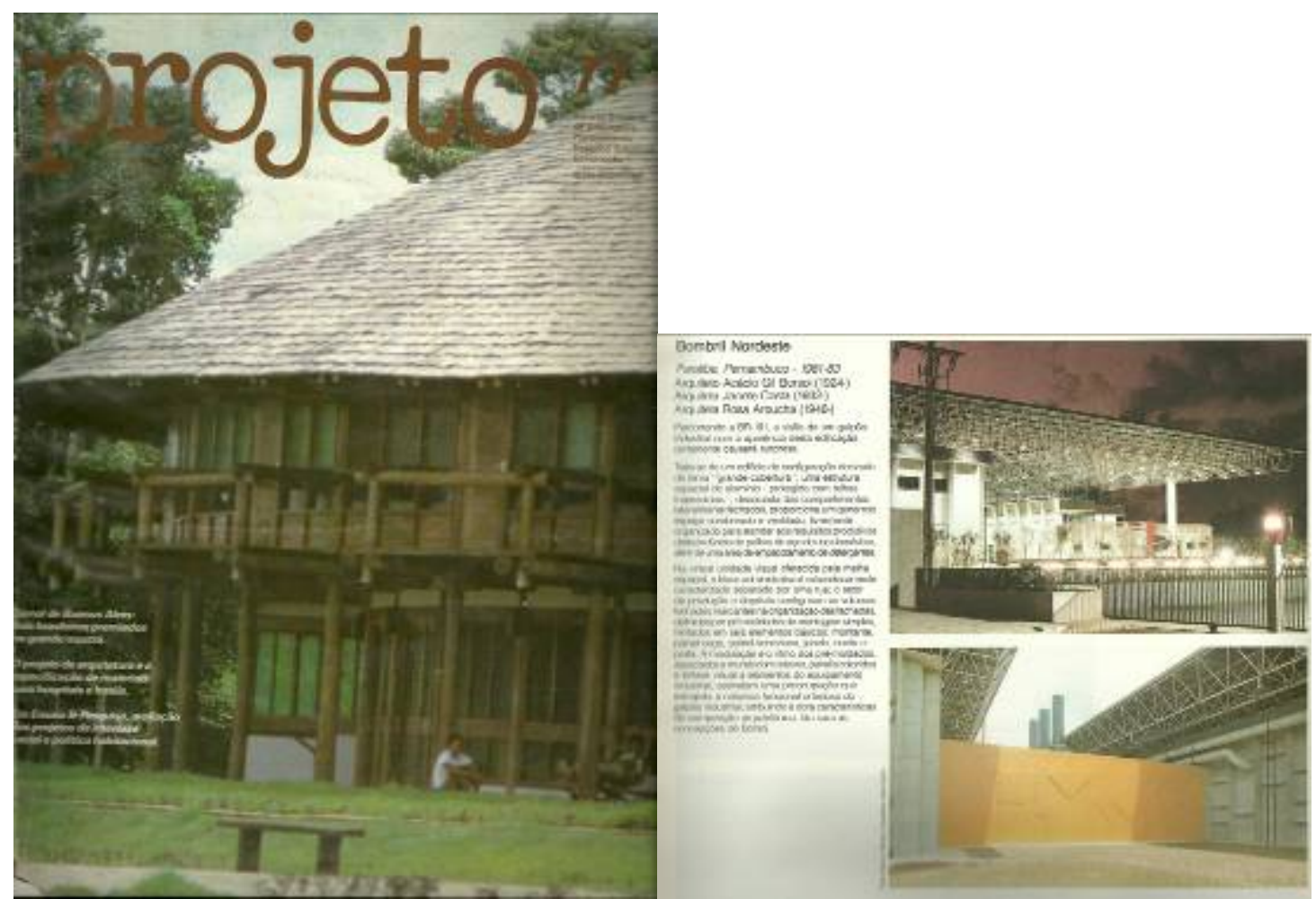

Figura 4. Publicação de 1985, na Revista Projeto, sobre o projeto da Fábrica da Bombril. Fonte: Projeto. 1985 . №77. 


\subsection{Sobre o autor e sua equipe de trabalho}

Acácio Gil Borsoi nasceu na cidade do Rio de Janeiro em 1924 e faleceu em São Paulo, em 2009, aos 85 anos de idade. Formou-se em 1949, pela Faculdade Nacional de Arquitetura da Universidade do Brasil, atual UFRJ, chegando a estagiar no escritório de Affonso Eduardo Reidy onde participou do projeto do Conjunto Habitacional do Pedregulho.

Em 1951, mudou-se para Recife onde se tornou professor da Escola de Belas Artes de Pernambuco durante vinte e oito anos, sendo um dos precursores da consolidação da arquitetura moderna no nordeste brasileiro, juntamente com os arquitetos e professores Mario Russo, Delfim Amorim, Heitor Maia Neto durante os anos 50, que foram os responsáveis pela criação espontânea de uma chamada "Escola do Recife".

Este momento foi pesquisado por Afonso (2006) em tese doutoral que tratou sobre a consolidação da arquitetura moderna em Recife, analisando o papel desses arquitetos, e de suas obras mais significativas que deram origem a esta "Escola"- apoiada por alguns críticos e não reconhecidas por outros.

O fato é que com a produção desses arquitetos docentes, adotando critérios projetuais modernos, dialogando arquitetura, lugar, clima, os projetos executados terminaram possuindo pontos convergentes de soluções, criando-se assim uma linha projetual.

A trajetória profissional de Borsoi pode ser dividida em três fases, conforme colocou Wolf \& Borsoi (1999): a primeira fase, que é referente à sua formação no Rio de Janeiro até o início dos anos 60, quando começou o momento marcado por um processo de reflexão ou releitura e revisão dos princípios modernos; uma segunda fase - quando abriu seu escritório em 1968, chegando a trabalhar com trinta profissionais, sendo um dos mais bem sucedidos escritório do país na época, projetando edifícios multifamiliares, institucionais, fábricas, entre outros; e a terceira fase, quando retoma algumas atividades na cidade do Rio de Janeiro, em 1989.

A fase analisada neste artigo, trata especificamente da segunda, quando o arquiteto carioca já estava devidamente consolidado profissionalmente no Recife, considerando que a Fábrica da Bombril foi projetada e construída entre os anos de 1979 a 1983. Sua equipe de desenvolvimento deste projeto contou com a participação de sua esposa Janete Costa (1932-2008) e Rosa Aroucha (1948-)

Janete Ferreira da Costa nasceu em 3 de junho de 1932, em Garanhuns (PE), e faleceu em 28 de novembro de 2008, em Olinda [PE]. Era arquiteta graduada pela Faculdade de Arquitetura da Universidade do Rio de Janeiro, em 1961. Trabalhou com arquitetura residencial, edifícios públicos, cinemas, auditórios e teatros; hotéis, prédios comerciais, restaurantes e lojas.

Janete Costa é considerada uma das principais arquiteta de interior brasileira, sendo uma das suas maiores contribuições, a divulgação da arte popular e do artesanato brasileiro. 0 ideal de Janete Costa era realizar o diálogo entre arte, arquitetura e design no Brasil, expressando as identidades culturais locais de cada região.

A arquiteta Rosa Aroucha foi aluna de Acacio Gil Borsoi, havendo estagiado com o professor e tornado-se, após a sua graduação, colaboradora de sua equipe, atuando em vários projetos desenvolvidos pela empresa. Após se desvincular do mesmo, criou sua própria empresa "Aroucha Associados Ltda.", na qual continuou desenvolvendo sua atividade como profissional liberal.

\subsection{Análise arquitetônica da Unidade fabril}

A Unidade da fábrica da Bombril em Pernambuco está localizada no Km 52, na BR-101 Norte, no município de Abreu e Lima, na Zona Industrial, Região Metropolitana do Recife (Figura 5). 0 complexo fabril possui $20.295 \mathrm{~m}^{2}$ de área construída, e é composto por três edifícios principais destinados inicialmente à produção de palha de aço. 


\section{Labor \& Engenho}

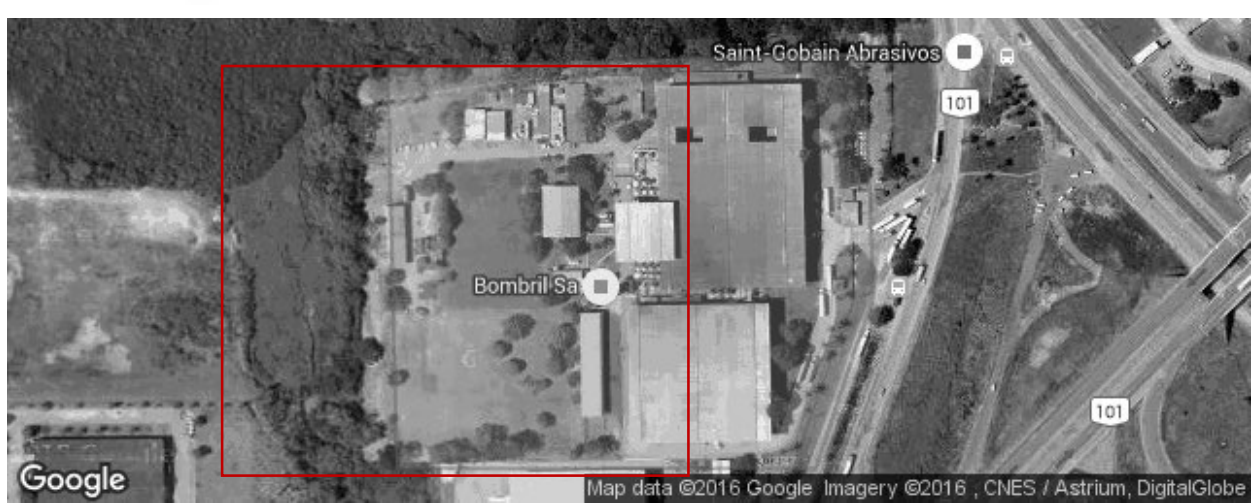

Figura 5. Localização da Fábrica da Bombril. Fonte: Google maps.

A implantação dos edifícios foi feita com os volumes separados, que se acomodam ao terreno com um pequeno declive, ao mesmo tempo em que atendem à lógica de produção. Os três volumes (Figura 6) atendem à funções diferenciadas: o primeiro acomoda a administração, o segundo foi destinado à produção e o terceiro ao armazenamento, estoque e centro de distribuição.

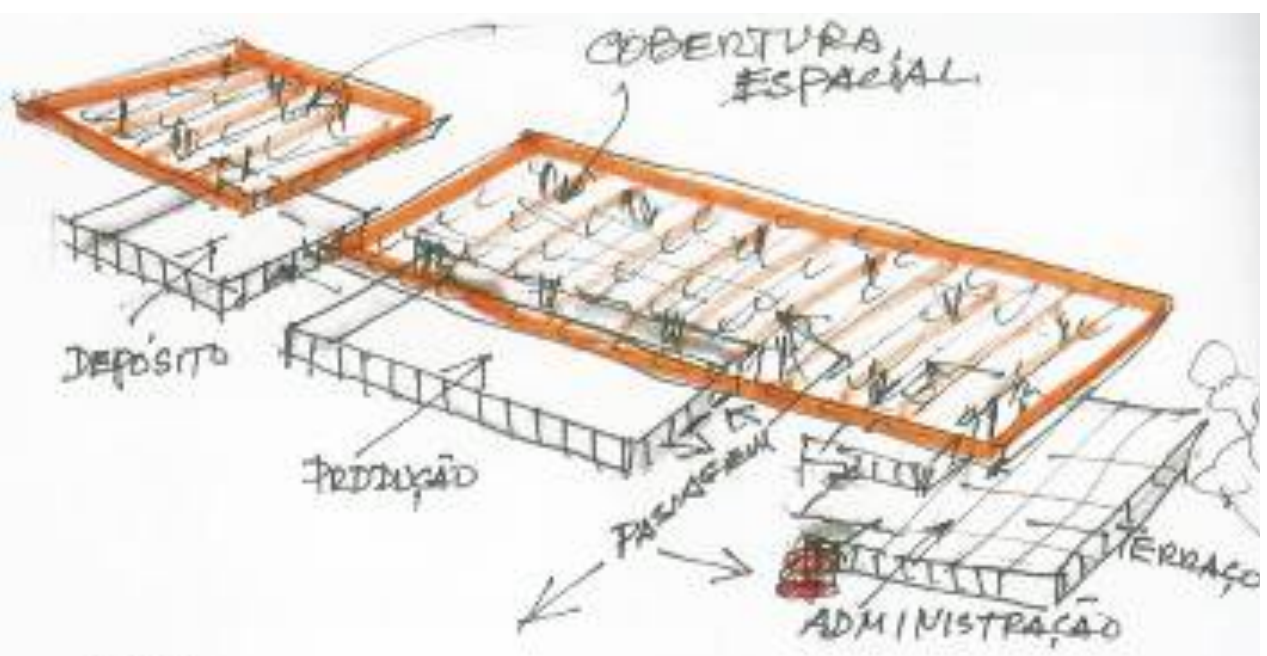

Figura 6. Esboço do arquiteto para solução projetual.

Fonte: Revista Projeto 77, p. 56-57. São Paulo, Arco Editorial, julho, 1985.

A análise arquitetônica dessa obra está voltada para sua dimensão tectônica, na qual, a observação dos sistemas estruturais é fundamental para a existência da mesma. Ching $(2015$, p.22) explica que "Os sistemas podem ser definidos como um conjunto de partes inter-relacionadas ou independentes que formam um todo mais complexo e unificado, servindo a um fim comum".

As edificações podem ser vistas como uma materialização de vários sistemas e subsistemas que precisam, necessariamente, estar relacionados, coordenados e integrados entre si, e também com a forma dimensional e com a organização espacial do prédio como um todo.

Certamente, Borsói e sua equipe entenderam que o sistema estrutural acomodaria e sustentaria, de maneira holística (compreendendo os fenômenos em sua totalidade e globalidade), as formas, os espaços e as relações programáticas e contextuais desse projeto arquitetônico.

Segundo Caldas \& Moreira (2012, p.170), duas características principais desse projeto foram os argumentos defendidos por seu autor: "A primeira foi o seu sistema de vedação com placas préfabricadas em concreto, desenhadas exclusivamente para o edifício, e a segunda foi a coberta em treliça metálica espacial."

Dessa forma, a estrutura utilizada na obra apresenta modulação em pré-moldados de concreto armado, sobre fundação em tubulões do mesmo material, superestrutura mista em concreto e aço, e cobertura em estrutura espacial de alumínio, que caracterizam essa obra de alta tecnologia para a época e ímpar plasticidade. 
As placas pré-moldadas foram utilizadas para o fechamento dos três blocos, empregando-se seis matrizes em madeira, permitindo a reprodução em fiberglas quantas formas/ moldes fossem necessárias para a unidade funcional/ compositiva, conforme escreveu o arquiteto Acacio Gil Borsoi:

Toda a fábrica foi projetada dentro de uma malha modular tridimensional $(m=1,25 \mathrm{~m})$, com os elementos pré-moldados, tanto os pilares como as placas de concreto, as quais constituem os panos de vedação (Revista Projeto, 1985).

Pode-se observar que o uso de uma modulação e o ritmo dos pré-moldados (Figura 7) dialogando com murais com relevos, paineis coloridos e ênfase visual a elementos de equipamento industrial, assinalam uma preocupação que extrapola a natureza funcional ortodoxa do galpão industrial, atribuindo à obra da Fábrica da Bombril, características de composição arquitetônica tão presente nas concepções de Borsoi.

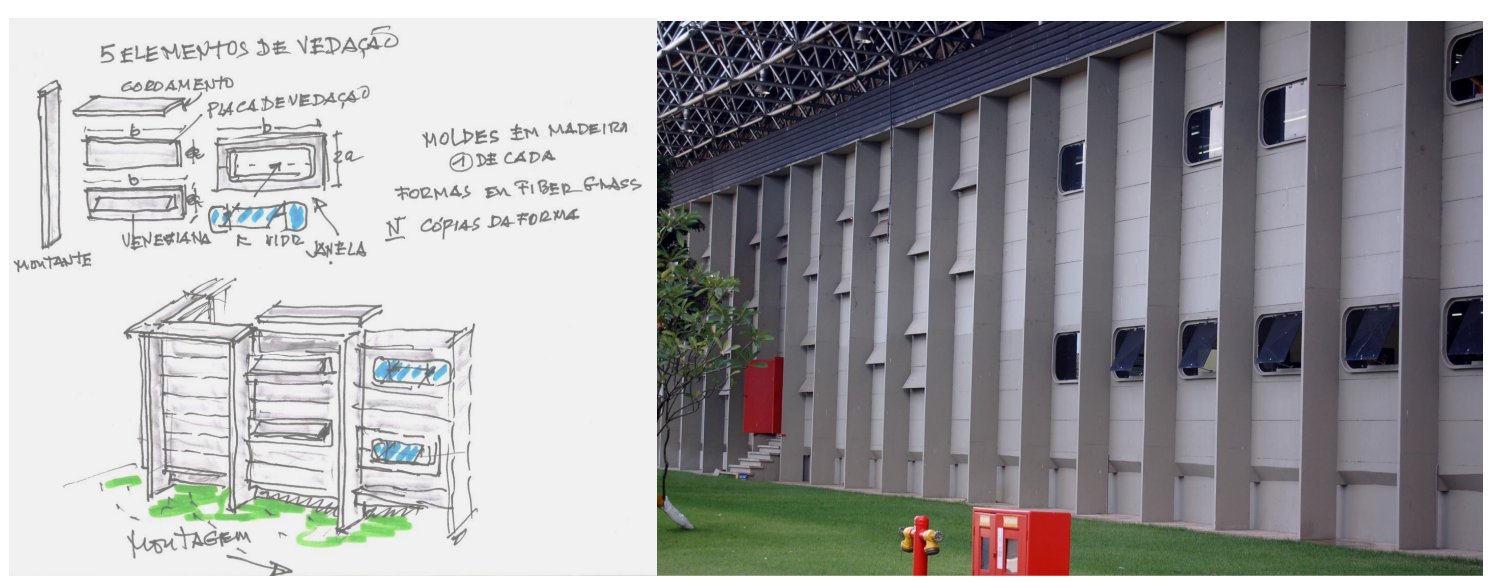

Figura 7. Esboços de Acacio Borsoi e fotografia dos paineis nas fachadas. Fonte: Borsoi. 2006.p. 39.

Quanto à segunda característica marcante do projeto, o arquiteto Acacio Gil Borsoi e sua equipe procurou inovar em sua proposta arquitetônica, propondo como partido "um edifício de configuração derivada do tema grande cobertura" - procurando um diferencial às soluções constantes na época para edifícios industriais, que adotavam os telhados em "shed" para resolver a cobertura de grandes vãos necessários aos espaços fabris.

Procurando atrelar as soluções da cobertura ao clima, propôs um grande pano de telhados para cada volume (Figura 8):

O partido adotado difere das soluções usuais de shed ou arco que caracterizam a edificação industrial. No nordeste com clima de temperaturas entre 25 a 37 graus, e uma brisa constante, a dissociação da coberta e das paredes cria uma grande sombra, protegendo do sol e da chuva, enquanto estas servem de vedação, mas garantindo a renovação de ar nos ambientes internos (Revista Projeto, 1985, p.56).

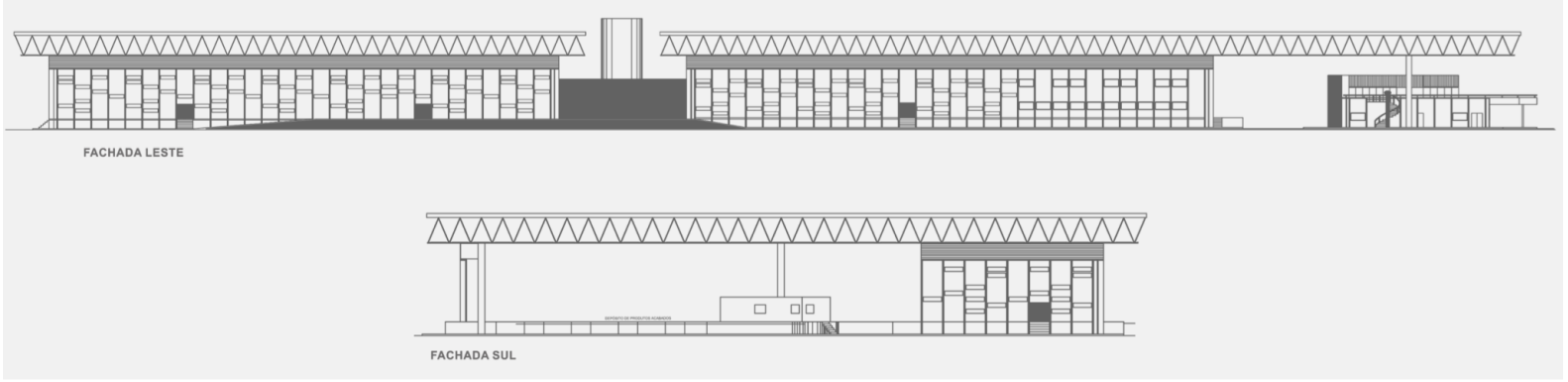

Figura 8. Fachadas da Fábrica da Bombril. Fonte: Grupo de pesquisas Arquitetura e Lugar.

Quanto à solução empregada para cobertura (Figura 9), desperta interesse à dissociação da mesma em relação às paredes, e a criação de uma grande área única e sombreada, protegendo os 
espaços internos do sol e da chuva, enquanto estas servem de vedação, garantindo a renovação de ar nos ambientes internos.

Ao analisar-se o uso da treliça espacial, como elemento compositivo e estrutural na obra da Fábrica, esclarece-se que a treliça é um elemento composto de um arranjo estável de barras delgadas interligadas, sendo um sistema estrutural muito econômico e útil para vencer grandes vãos, sendo muito empregada em coberturas e pontes, conforme colocou Rebello (2002).

0 padrão das barras, que frequentemente subdivide a treliça em áreas triangulares, é selecionado para produzir um membro de apoio leve e eficiente: frequentemente pode ser considerada como uma viga da qual o material excedente foi removido para reduzir o peso, e as cordas da treliça correspondem às mesas da viga (Leet, 2010).

Segundo Barroso (2004), as vantagens em se utilizar as treliças espaciais, se deve à sua composição geométrica e à natureza de seus elementos, as malhas espaciais que apresentam maior resistência global face às cargas de ruptura; onde sua barra fabricada a partir de perfis tubulares tem excelente comportamento quanto à flambagem local ou por torção.

Outro ponto importante é quanto a poder vencer maiores vãos com menor gasto de materiais, bem como, devido à simplicidade de seus elementos construtivos- a barra e o nó, a fabricação, transporte e montagem é extremamente facilitada, cabendo aos operadores em campo a simples tarefa de apertar parafusos, observando-se assim que edificações cobertas com malhas espaciais são de um modo geral mais econômicas que as com coberturas convencionais.

Uma informação importante para a compreensão da opção de Borsoi em usar tal solução projetual, é saber que no Brasil, a primeira treliça espacial importante surgiu no ano de 1970: A cobertura do Pavilhão de Feiras e Exposições do Anhembi, projetada com barras tubulares em alumínio, pelo engenheiro anglo-canadense Cedric Marsh, e montada pela empresa Fichet Engenharia (Barroso, 2004). 0 pesquisador explica que [...]

[...] com o aparecimento de sistemas computacionais e softwares de cálculo estrutural mais acessíveis, facilitando sobremaneira o projeto, a partir de 1977, as malhas espaciais ficaram mais populares e caíram no gosto dos arquitetos e investidores do momento (Barroso, 2004).

As primeiras malhas espaciais surgidas no Brasil, por imposição de mercado, foram projetadas em alumínio. Hoje, no entanto, 95\% são produzidas com tubos de seção circular em aço. A utilizada na Fábrica da Bombril foi em alumínio e foram colocadas telhas trapezoidais de alumínio.

Esse momento de emprego de novas tecnologias influenciou o arquiteto e sua equipe, que inovou no nordeste brasileiro, trazendo a proposta para o projeto da Fábrica da Bombril, e influenciando outros profissionais que recebiam encomendas projetuais na área industrial, bastante demandada pela política da Superintendência de Desenvolvimento do Nordeste (SUDENE) nesses anos.

Observa-se que, as soluções projetuais e construtivas, priorizaram uma composição que valorizou a forma atrelada às soluções estruturais da cobertura, criando planos horizontais externamente, e tridimensionais no espaço interno, obtendo como resultado, um ambiente integrado, transparente - solução inédita até então, para um projeto de uma fábrica construída na região do nordeste brasileiro.

Afirma-se tal posicionamento, ao constatar nos esboços do arquiteto a sua busca em obter um espaço funcional, racional, porém, rico e leve esteticamente, provando-se que é possível projetar edificações de tipologia industrial com qualidade arquitetônica.

Depois de analisar a edificação e suas soluções projetuais e técnico construtivas, pode-se constatar a utilização da linguagem brutalista, adotando a fidelidade dos materiais, sem acabamentos; as instalações e estruturas aparentes e o uso do concreto que predominou nas placas pré-moldadas. 

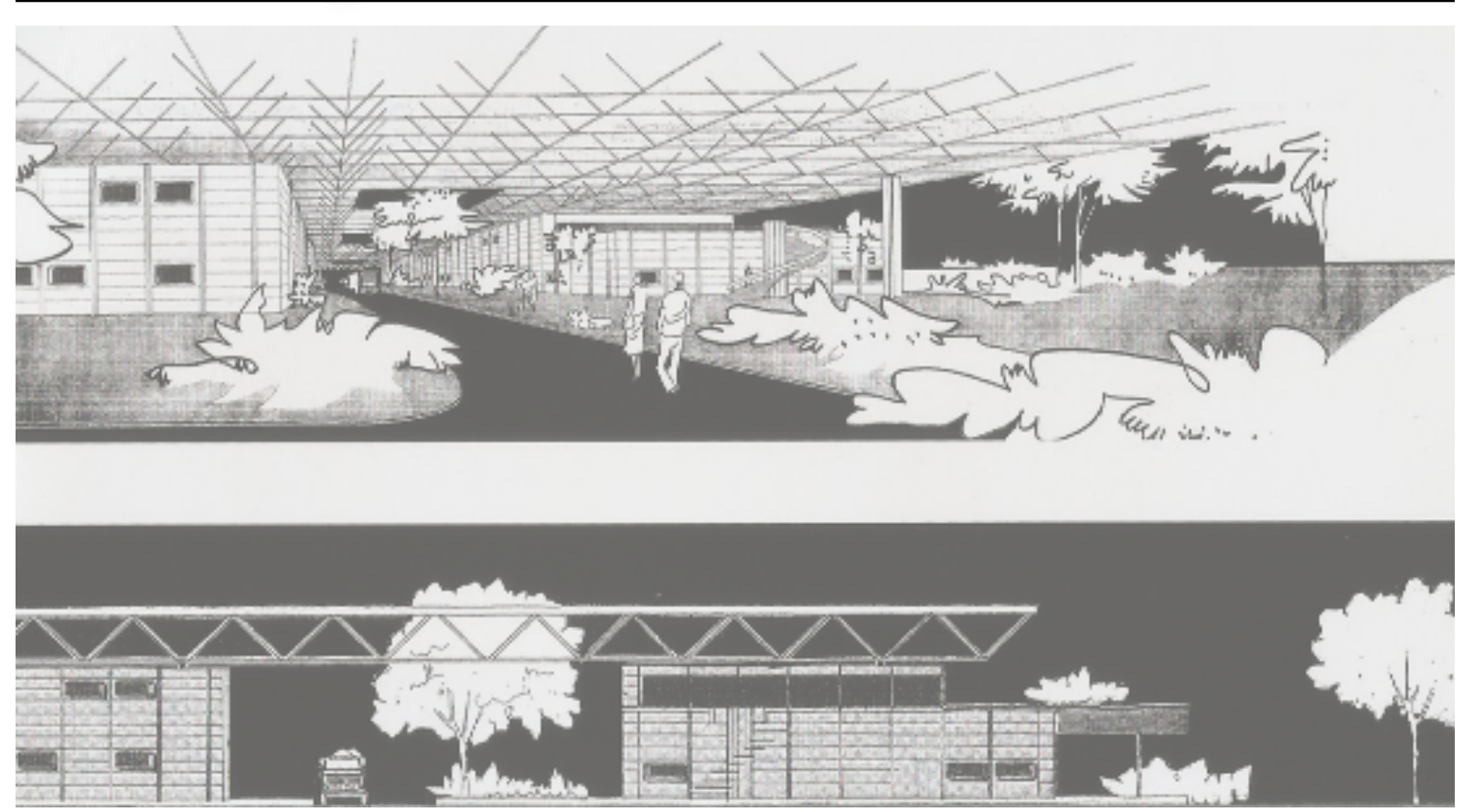

Figura 9. Esboços de Borsoi para o partido arquitetônico da Fábrica da Bombril. Fonte: Revista Projeto 77, p. 56-57. São Paulo, Arco Editorial, julho, 1985.

Sem dúvida, o arquiteto adotou a "estética do concreto", presente nas obras do mestre Le Corbusier em um primeiro momento, e posteriormente, retomada com o novo brutalismo.

Na modernidade arquitetônica, a relação estrutura/ arquitetura sempre esteve muito presente, sendo adotada como um dos princípios fundamentais durante o processo de concepção projetual. Borsoi foi um arquiteto que com uma formação baseada em princípios de modernidade (Afonso, 2006), acreditava que não se pode imaginar uma forma que não necessite de uma estrutura, ou uma estrutura que não tenha uma forma. Toda forma tem uma estrutura e toda estrutura tem uma forma.

Na verdade, a concepção de uma forma implica na concepção de uma estrutura e, em consequência, dos materiais e processos para materializá-la. A estrutura e a forma são um só objeto, e, assim sendo, conceber uma, implica em conceber outra e vice-versa.

Quem cria a forma, cria a estrutura: A forma e a estrutura nascem juntas. Segundo Rebello (2000, p.26), conceber é compreender, entender e ser capaz de explicar. E observa-se que Borsoi apoiado em princípios projetuais firmes procurava desenvolver seus projetos embasados nesse critério.

\section{Conclusão}

A proposta deste artigo foi trazer à tona um exemplar arquitetônico com tipologia industrial que utilizou soluções projetuais e construtivas embasadas em princípios de modernidade - o emprego de plantas livres, estruturas independentes, espaços transparentes, atenção ao detalhe construtivo, caracterizando tal partido.

A boa arquitetura que o professor e arquiteto Acacio Gil Borsoi produziu nessa obra, reafirma o valor em documentar, conservar e divulgar a mesma. Um exemplo a ser seguido, observado, a fim de retirar dela, as soluções projetuais tais como o estudo dos pré-moldados e suas distintas formas de aplicação, e a grande cobertura que interliga e une os diferentes espaços, com seu arrojo estrutural.

Uma obra na qual se observou que para solucionar o complexo programa industrial, o projeto arquitetônico dialogou constantemente com a concepção estrutural, nos reportando a uma colocação de Ching (2015) que escreveu sobre essa relação: 
A intenção formal de um projeto de arquitetura pode ser sugerida ou determinada pelo terreno e pelo contexto, pelo programa e pela função, ou pelos objetivos e pelo significado. Além de considerar as opções formais e espaciais, também devemos contemplar nossas opções estruturais (a palheta de materiais, os tipos de apoios e elementos horizontais, os sistemas de resistência aos esforços laterais) (Ching, 2015, p.25).

O autor conclui que tais escolhas são capazes de influenciar, sustentar e reforçar as dimensões formais e espaciais de um projeto. Tais decisões vêm em primeiro lugar, determinando a direção e estabelecendo parâmetros para o desenvolvimento projetual e de detalhes - que foi o que ocorreu nessa obra. A precisão e a preocupação com todo o processo projetual e construtivo sempre esteve presente de forma bastante clara.

Após quase quatro décadas que foi inaugurada, a obra sofreu poucas descaracterizações, e mantém o seu uso original, e continua com a produção da linha Bombril.

As mudanças maiores sofridas são referentes ao seu entorno, que ao longo desses anos, recebeu a implantação de um maior número de indústrias, mas que, não possuem edificações com tanta qualidade arquitetônica como edifício em questão. Devida à proliferação dos edifícios industriais, a Unidade apresenta-se de forma bastante discreta na paisagem atual, passando despercebida naquela rodovia.

Interiormente, alguns painéis artísticos que interligavam os blocos foram modificados, pois anteriormente possuíam formas geométricas nas cores da embalagem do produto Bombril (amarelo, vermelho, branco), e atualmente estão revestidos com pintura chapada em vermelho.

A unidade da Bombril em Pernambuco não está inventariada no rol de edificações modernas a serem protegidas pelas instituições de preservação do município de Abreu e Lima, nem do Governo de Pernambuco. É um exemplar de grande valor arquitetônico, e que infelizmente, devido a estar produzindo, sofrerá possíveis modificações para acomodações às novas tecnologias industriais.

Situação dualista, pois se por um lado é bom que a indústria mantenha ao longo dos anos seu uso, por outro, está sujeita a sofrer reformas, acréscimos, que podem descaracterizar o projeto original. Por isso, a necessidade de documentar, divulgar, interagir o conhecimento arquitetônico com demais discussões pertinentes ao patrimônio industrial e suas distintas vertentes de atuação.

Há que se continuar investigando, observando, descobrindo mais valores da obra moderna industrial produzida em regiões brasileiras, como as existentes no norte e nordeste - ainda tão pouco estudadas e difundidas.

Aponta-se para a necessidade que existe em se proteger tais patrimônios, possuidores de valores ainda não reconhecidos por organismos preservacionistas e que fazem parte de acervos recentes. Cabe a nós, pesquisadores, iniciar este trabalho de sensibilização, de educação, para a valorização do patrimônio moderno industrial brasileiro.

\section{Referências}

Afonso, A. (2006). La consolidación de la arquitectura moderna en Recife en los años 50. (Tese de doutorado) UPC, ETSAB, Departamento de projetos arquitetônicos, Barcelona.

Afonso, A. (org) (2017). Modernidade no norte nordeste brasileiro. O diálogo entre arquitetura, tectônica e lugar. Teresina: EDUFPI.

Amaral, I. (2001). Mil e uma utilidades: a fábrica da Bombril em Pernambuco - o sofrimento do edifício e o processo caboclo de industrialização. In Anais do IV Seminário Docomomo-Brasil: a industrialização brasileira e as novas técnicas construtivas. Viçosa e Cataguases.

(C) Labor \& Engenho, Campinas [SP] Brasil, v.12, n.3, p.378-391, jul./set. 2018. 
Amaral, I. (s.d.). Quase tudo que você queria saber sobre tectônica, mas que tinha vergonha de perguntar. Recuperado de: http://www.revistas.usp.br/posfau/article/viewFile/43644/47266. Janeiro 2009.

Barroso, P. A. B. (2004). Aplicação das Malhas Espaciais na Arquitetura. +MAIS Arquitetura. Agosto. Recuperado de: http://wwwo.metalica.com.br/aplicacao-das-malhas-espaciais-na-arquitetura .

Borsoi, A. G. (2006). Arquitetura como manifesto. Recife: Gráfica Santa Marta.

Borsoi, M. A. \& Wolf, J. Documento: Acácio Gil Borsoi. Arquitetura e Urbanismo, 84.pp 35-41.

Caldas, R. (2010). Arquitetura Industrial em Recife: uma face da modernidade. (Dissertação de mestrado) Universidade Federal de Pernambuco Recife. CAC. Desenvolvimento Urbano, $180 f$.

Caldas, R. M. V., \& Moreira, F. D. (2012). Arquitetura Industrial: técnica, detalhe e significância. Cadernos UFRJ. Proarq, 18. Recuperado de: http://cadernos.proarq.fau.ufrj.br/pt/paginas/edicao/18.

The International Committee for the Conservation of the Industrial Heritage TICCIH (2003) Carta de Nizhny Tagil Sobre o Patrimônio Industrial, Nizhny Tagil, Recuperado de: http://ticcih.org/wp-content/ uploads/2013/04/NTagilPortuguese.pdf

Ching, F. et al. (2015) Sistemas estruturais ilustrados: padrões, sistemas e projeto. Porto Alegre: Bookman.

Choay, F. (2006) A Alegoria do Patrimônio. 4ed. São Paulo: Estação Liberdade.UNESP.

Costa, L. (1995) Considerações sobre arte contemporânea (1940). In: Lúcio Costa, Registro de uma vivência. São Paulo: Empresa das Artes.

Edifício Industrial: adequação ao clima em solução industrial modulada, Bombril Nordeste (1995). Projeto 77, pp. 56-57. São Paulo, Arco Editorial, julho.

Frampton, K. (1995) Studies in tectonics culture. Cambridge. Massachussets: The MIT Press.

Frampton, K. (1990) Towards a critical regionalism: Six points for an architecture of resistance. In: Frampton, K. Rappel à l'Ordre : the Case for the Tectonic. Architectural Design, Londres, 60 (3-4), 1925p.

Leet, K. M. et al (2010).Fundamentos da análise estrutural, 3ed. Porto Alegre: AMGH Editora.

Mahfuz, E. (2004). Reflexões sobre a construção da forma pertinente. Arquitextos, São Paulo, Vitruvius, 4 (45) Recuperado de: <http://www.vitruvius.com.br/revistas/read/arquitextos/04.045/606>.

Rebello, Y. C. P. (2000). A Concepção Estrutural e a Arquitetura. Editora Zigurate, São Paulo.

Sekler, E. (1965) Structure, construction, tectonics. In: Kepes, Gyorgy (Org.). Structure in art and in science. Nova York: George Braziller, pp. 89-95.

Weidle, E. et al.(1995). Sistemas Construtivos na Programação Arquitetônica de Edifícios de Saúde. Série Saúde \& Tecnologia, Textos de Apoio à Programação Física dos Estabelecimentos Assistenciais de Saúde, Brasília. 